\title{
A Teaching Experiment of Chinese College Students' English Idioms Comprehension
}

\author{
https://doi.org/10.3991/ijet.v12i06.7096 \\ Hui Chen \\ Guangxi Normal University for Nationalities, Chongzuo, China \\ chenhe813@126.com \\ Xianze $\mathrm{Wu}^{*}$ \\ Guilin University of Technology, Guilin, China \\ moiwxz@126.com
}

\begin{abstract}
An English idiom is a special combination of words, the meaning of which is not the simple addition of its constituents but a special meaning. English idioms are widely used by English native speakers, which are very important for English as a second language learners. Chinese learners are poor in English idioms comprehension, and they need to adopt a new method for improving their English idioms comprehension. S-S-P-C model means analyzing an English idiom from syntactic, semantic, pragmatic, and cultural perspective, which was applied in a teaching experiment among college students for one semester. The teaching experiment shows that S-S-P-C model is an efficient method for Chinese learners to help improve their English idioms comprehension.
\end{abstract}

Keywords-Teaching experiment; English Idioms comprehension; Chinese learners

\section{Introduction}

English idioms are widely used by English native speakers in daily conversation and written language ${ }^{[1]}$ For English as a second langue learners, grasping a suitable amout of English idioms is very necessary, which signifies how well he or she learns the Englihs language. However, English idioms comprehension and acquisition is a tough task for most of Chinese learners, who spend lots of time on English learning but achieve less. Chinese learners attach great importance to English words, neglecting English idioms. What are idioms? The definition of idioms vary from each other in different languages. The Chinese language is a long-history language, which boasts of a large amount of vocabulary. "In Chinese lexical system, Chinese idioms are a typical unit. As an individual type in the domain of idioms, most Chinese idioms have some unique qualities. One of the design features of most Chinese idioms on the dimension of form characteristics is the four-character form----- the Chinese lexicon provides an exact number of the characters in such a unit." ${ }^{[2]}$ Different from Chines 
idioms, English idioms are "metaphor, indirect speech acts, sarcasm, irony, metonymy, and many other linguistic constructions". ${ }^{[3]}$ Idioms as multiword expressions are lexicalized: "they have the semantic unity of single words but the grammatical flexibility, though in varying degrees, of phrases, semi-clauses, and clauses, which indeed the majority is". ${ }^{[4]}$ An English idiom is a combination of more than one word, the meaning of which is not the simple addition of its constituents' literal meanings. The meaning of an English idiom cannot be deduced from the literal meanings of the individual words constituenting the idiom. Therefore, Chinese learners should adopt a different method when comprehending or acquiring English idioms.

Based on previous reseach, we proposed a model of English idioms comrehension, which is called S-S-P-C model. In this model, the first S stands for syntactic analysis, the second $\mathrm{S}$ stands for semantic analysis, the $\mathrm{P}$ stands for the pragmatic perspective, and the $\mathrm{C}$ stands for the cultural perspective. Specifically speaking, when comprehending an English idiom, a learner can try to analyze the idioms from the four aspects: syntactic, semantic, pragmatic, and cultural. Take the idiom "come true" as an example. Syntactically, "come true" can be sorted into the pattern of Verb + Complement. Therefore, it will bear some characteristics of this pattern. "Come true" will act a predicate like a pattern of Verb + Complement. Only has a student grasped the grammatical usages of "come true", he can make correct sentences, like "my dream has come true". Otherwise, he may make wrong sentences, like "my dream is come true". Some other idioms can be set about like that from the perspective of semantics, pragmatics, and cutural. In order to examine whether this model of English idioms comprehension was efficient, we conducted a teaching experiment of the S-S-P-C model of English idioms comprehension among college students for one semester.

\section{Experimental section}

\subsection{Pre-test and a Group Interview}

Before beginning the teaching experiment of S-S-P-C model, we conducted a pretest and a group interview. We chose college students as subjects. The students, who were non-English majors, were sophomores from Guangxi Normal University for Nationalities. The students' majors cover Chinese majors, Law majors, Physics majors, Chemistry majors, and so on. All students from ten classes participated in the pre-text. Forty two students were from Class One, which would be the contrastive class, and forty students were from Class Two, which would be the teaching experiment class. The number of students from Class Three to Ten ranged from forty to forty-three. We chose forty English idioms randomly from Oxford Dictionary of Idioms edited by Judith Siefring as the material for the pre-text. The forty English idioms were not included in the subjects' textbooks. The subjects were expected to translate the English idioms into Chinese. If an idiom was translated correctly,the subject would score 2.5 marks, or else he would score zero. The scores were analyzed by SPSS 17.0. Ten classes' scores of English idioms test are displayed in Table 1. 
Table 1 shows that average scores of each class range from 30 to 35 . The average scores of Class 1, which will be the contrastive class, are 29.10; Std. Deviation is 14.062; Std. Error is 2.170; Lower Bound of 95\% Confidence Interval for Mean is 24.71; Upper Bound is 33.48. In contrast, Class 2 will be the teaching experiment class, and its average scores are 33.35; Std. Deviation is 15.448; Std. Error is 2.443; Lower Bound of $95 \%$ Confidence Interval for Mean is 28.41; Upper Bound is 38.29. The low average scores of English idioms test indicate that students from the ten classes are very poor in English idioms learning, including the would-be contrastive class and the teaching experiment class. In order to examine whether there were significant differences in English idioms learning between the ten classes, we conducted test of homogeneity of variances and one-way Analysis of Variance (Anova).

In Table 2, which is the result of the test of homogeneity of variances, $\mathrm{P}=.204>0.05$, which shows that the data is suitable for one-way anova.

The one-way Anova in Table 3 shows that $\mathrm{P}=.211>0.05$, which demonstrates that there is no significance difference between different groups.

Table 1. Ten Classes' scores of English Idioms Test

\begin{tabular}{|c|c|c|c|c|c|c|}
\hline \multirow{2}{*}{ Class } & \multirow{2}{*}{$\mathbf{N}$} & Mean & \multirow{2}{*}{ Std. Deviation } & \multirow{2}{*}{ Std. Error } & \multicolumn{2}{|c|}{ 95\% Confidence Interval for Mean } \\
\cline { 6 - 7 } & & & & & Lower Bound & Upper Bound \\
\hline 1 & 42 & 29.10 & 14.062 & 2.170 & 24.71 & 33.48 \\
\hline 2 & 40 & 33.35 & 15.448 & 2.443 & 28.41 & 38.29 \\
\hline 3 & 43 & 36.95 & 15.933 & 2.430 & 32.05 & 41.86 \\
\hline 4 & 41 & 35.51 & 16.078 & 2.511 & 30.44 & 40.59 \\
\hline 5 & 41 & 32.56 & 14.342 & 2.240 & 28.03 & 37.09 \\
\hline 6 & 43 & 31.47 & 14.494 & 2.210 & 27.00 & 35.93 \\
\hline 7 & 43 & 29.09 & 12.939 & 1.973 & 25.11 & 33.08 \\
\hline 8 & 41 & 35.12 & 15.603 & 2.437 & 30.20 & 40.05 \\
\hline 9 & 41 & 33.49 & 15.611 & 2.438 & 28.56 & 38.42 \\
\hline 10 & 43 & 31.16 & 13.327 & 2.032 & 27.06 & 35.26 \\
\hline Total & 418 & 32.76 & 14.862 & .727 & 31.33 & 34.19 \\
\hline
\end{tabular}

Table 2. Test of Homogeneity of Variances

\begin{tabular}{|c|c|c|c|}
\hline Levene Statistic & df1 & df2 & Sig. \\
\hline 1.361 & 9 & 408 & .204 \\
\hline
\end{tabular}

Table 3. One-way Anova

\begin{tabular}{|l|c|c|c|c|c|}
\hline & Sum of Squares & df & Mean Square & F & Sig. \\
\hline Between Groups & 2656.808 & 9 & 295.201 & 1.347 & .211 \\
\hline Within Groups & 89445.788 & 408 & 219.230 & & \\
\hline Total & 92102.596 & 417 & & & \\
\hline
\end{tabular}


In conclusion, the pre-test shows that college students from the ten classes are poor in English idioms learning and there is no significance difference between different classes, which lays a foundation for our further study.

In order to know the ins and outs of students' acquiring English idioms, we conducted a group interview. Six students among teaching experiment class were chosen randomly to be interviewed. The interviewed questions are: Do you think English idioms are more difficult than words? How do you learn English idioms?

About the first question, all the interviewed students admitted that English idioms were much harder to learn than English words and they felt frustrated about idioms learning. As to the second question, students gave different replies, which are transcribed as follows:

Student A: I have no special methods. When I learn English words, I try to memorize their spellings and their equivalent Chinese meanings by rote learning. I think idioms are just like words, so I adopt the same methods.

Student B: I have no special methods, either. An English idiom has an equivalent Chinese meaning. I have to memorize it just like a word. For example, put across, one meaning of which is to express, is just like a word. I cannot get its meaning by adding the meaning of "put" with the meaning of "across", so I have to remember that "put across" means "express", and I use the idiom "put across" in a sentence just like I use the word "express".

Student C: Idioms are special, which are somewhat different from words. For some idioms, I learn them by rote learning, such as "pick up", "bring up", "put across", each of which is a single unit, just like a word. For some idioms, I can link them to other things. For example, "be the last straw" is an interesting idiom. When I come across it, I remember that there is a nearly same saying in Chinese, so I conclude that it must be the same meaning as the saying in Chinese. However, this sort of idioms are not many; moreover, sometimes an English idiom has a completely different meaning from that seemingly similar Chinese equivalent, such as "eat ones words", which is nearly the same as "Shi Yan". "Eat ones words" means that "confess that one's predictions were wrong", which is completely different from "Shi Yan" with the meaning of "someone failed to do what is promised". So, I think rote learning is the best method, which can guarantee the meanings of idioms are understood as it should be.

Student D: I cannot agree with Student C more. Sometimes I speculate there may be a better way to learn idioms, and I try to link the English idiom with the Chinese idiom. Sometimes I can guess the meanings of some English idioms, but sometimes not. When I make a mistake, I am at a loss. So, I would rather learn idioms by rote learning, which is safe.

Student E: Learning idioms by rote learning are actually safe, but it is boring. We cannot remember so many things only by rote learning. I tried to find out some convenient and efficient method, but I failed. I expect maybe there is not such a method.

Student F: Actually, idioms learning are important, and I learn them by rote learning. However, when I come across a new idiom, I have to look up it in a dictionary, which makes me fail to concentrate on the story what I am reading. I am eager for an efficient idioms learning method. 
From the interview transcriptions, we can make a summary about what students think of English idioms acquisition: English idioms are important, which should be attached great importance; An idiom is just like a word, which can be learned only like a word by rote learning; For English idioms acquisition, there are not an efficient method.

According to the pre-test and the interview, we can get to know the current situation about students' English idioms comprehending and acquisition: Chinese college students have great difficulties in comprehending and acquiring English idioms. They always acquire English idioms by adopting the traditional method-----rote learning. They are not interested in English idioms and often avoid using idioms in both oral communication and written communication. They need some new English idioms acquisition methods badly.

\subsection{The Application of S-S-P-C Model in College English Teaching}

After the pre-test and the group interview, we began a teaching experiment. The teaching experiment lasted for one semester. We chose Class 2 as the teaching experiment class, and Class 1 as the contrastive class. In the teaching experiment class, there are 40 students, who major in Chinese. In the contrastive class, there are 42 students, who major in Chemistry. In the contrastive class, we adopted traditional teaching method. In other words, we attached no importance to English idioms teaching and acquisition, and we spent very little time on it or taught students to remember spellings and usages of those idioms as words. In the teaching experiment, we adopted the S-S-P-C model of English idioms acquisition. In other words, both the teacher and the students attached great importance to English idioms acquisition, and they saw idioms as special language elements. Specifically, the teacher taught idioms from the four perspectives: syntactic, semantic, pragmatic, and cultural.

The following is the procedure of teaching an idiom:

We take the idiom carry coals to Newcastle as an example. When teaching carry coals to Newcastle, the teacher instructs the students to analyze its syntactic structure. From the syntactic perspective, carry coals to Newcastle belongs to clause idioms and can be subcategorized into the pattern of Verb + Direct Object + adjunct. Therefore, the students can grasp grammatical usages of carry coals to Newcastle. In other words, the students will use it as a verb in a sentence instead of a noun. From the semantic perspective, the teacher analyzes its semantic meaning. The key word in this idiom is Newcastle, which is famous for boasting of lots of coals. The teacher tells students this knowledge and instructs students to speculate its semantic meaning from "carry coals to Newcastle, which boasts of lots of coals", and it is very easy for students to acquire its figurative meaning which is "do something necessary" from "carry coals to Newcastle, which boasts of lots of coals". The reasoning is as such: Newcastle boasts of coals; if you carry coals to Newcastle, the coals will be more; For Newcastle, increasing some coals brings no advantages. Therefore, carrying coals to Newcastle means "do something necessary". Then, the teacher will give some examples: you are carrying coals to Newcastle, because her family is rich and she is not short of money at all. From the pragmatic perspective, the idiom carrying coals to 
Newcastleis colloquial and is used in daily conversation in most cases. From the cultural perspective, carrying coals to Newcastlehas no special cultural origin. As illustrated above, the idiom carrying coals to Newcastle has been analyzed from the four perspectives: syntactic, semantic, pragmatic, cultural, which is the S-S-P-C model.

"Cold turkey" is another good example. Syntactically, it belongs to the phrase idiom and is subcategorized into the pattern of noun phrase, so the students get to know it acts as grammatical functions of a noun phrase. Semantically, it is difficult for us to deduce its figurative meaning from "cold" and "turkey". Nevertheless, we can explore its origin from the perspective of culture. Turkey is a very important dish in English family on both Thanksgiving Day and Christmas Day. However, different from chicken on Chinese plates, in English families' eye, turkey is not only ugly but also dull. Imagine what is a cold turkey like? Therefore, if you are called "a turkey", you must be very angry, because you can deduce its meaning is stupid or something from its cultural origin ${ }^{[5]}$. Pragmatically, it is colloquial and is used in daily conversation. Also, the idiom cold turkey has been analyzed under the guide of S-S-P-C model of English idioms acquisition.

Following the S-S-P-C model, the teacher analyzes some idioms as examples. Later on, for every new idiom, students try to analyze from the four perspectives guided by the teacher. From the feedback, students are very interested in this model and are ready to analyze idioms they come across.

\section{Results and Discussion}

After the teaching experiment was over, we conducted a post-test on Class Two as the teaching experiment class, and Class One as the contrastive class. The test material was another forty idioms randomly chosen from Oxford Dictionary of Idioms edited by Judith Siefring. The forty idioms were not included in the subjects' textbooks and different from those in the pre-test. In order to guarantee the materials of pre-test and post-test have similar degrees of difficulties, we chose Class Three as subjects. The forty-one students from Class Three, who received no teaching experiment, were asked to be tested on the materials of post-test. The scores of the pre-test and the posttest were examined by paired samples statistics and paired samples test. The results are shown in Table 4 and Table 5.

As seen from Table 4, average score of pre-test is 31.32, and that of post-test is 33.63. Standard deviation in Pre-test is 12.960 , and that in Post-test is 12.545 .

Table 4. Paired Samples Statistics

\begin{tabular}{|l|c|c|c|c|}
\hline & Mean & N & Std. Deviation & Std. Error Mean \\
\hline Pre-test & 31.32 & 41 & 12.960 & 2.024 \\
\hline Post-test & 33.63 & 41 & 12.545 & 1.959 \\
\hline
\end{tabular}

The paired sample test in Table 5 shows that Mean Difference between pre-test and post-test of Class Three is -2.317 , and $t$ is -9.54 ; Two-tailed test is not significant ( $\mathrm{P}=0.346>.05$ ), which demonstrates there are no significant differences between 
scores of two tests. In other words, the materials of pre-test and post-test have similar degrees of difficulties.

Table 5. Paired Sample Test

\begin{tabular}{|c|c|c|c|c|c|c|c|}
\hline \multicolumn{5}{|c|}{ Paired Difference } & \multirow{3}{*}{$\mathbf{t}$} & \multirow{3}{*}{ df } & \multirow{3}{*}{$\begin{array}{l}\text { Sig. }(2- \\
\text { tailed) }\end{array}$} \\
\hline \multirow{2}{*}{ Mean } & \multirow{2}{*}{ Std. Deviation } & \multirow{2}{*}{$\begin{array}{l}\text { Std. Error } \\
\text { Mean }\end{array}$} & \multicolumn{2}{|c|}{$\begin{array}{c}95 \% \text { Confidence } \\
\text { Interval of the Difference }\end{array}$} & & & \\
\hline & & & Lower & Upper & & & \\
\hline-2.317 & 15.546 & 2.428 & -7.224 & 2.590 & -.954 & 40 & .346 \\
\hline
\end{tabular}

After the material of post-test was examined by paired sample test, we conducted the post-test on Class Two as the teaching experiment class, and on Class One as the contrastive class. The method is the same as what the pre-test adopted. In other words, the subjects were expected to translate the English idioms into Chinese. If an idiom was translated correctly, the subject would score 2.5 marks, or else he would score zero. The data was analyzed by SPSS 17.0. The descriptive statistics in Table 6 shows that the average score of the contrastive class is 33.42 , and that of the teaching experiment class is 68.51. After the teaching experiment was conducted, the experiment class scored 68.51, much higher than the contrastive class, which scored only 33.42 .

Table 6. Group Statistics

\begin{tabular}{|c|c|c|c|c|}
\hline Class & N & Mean & Std.Deviation & Std.ErrorMean \\
\hline 1 & 43 & 33.42 & 14.221 & 2.169 \\
\hline 2 & 40 & 68.51 & 11.409 & 1.740 \\
\hline
\end{tabular}

Independent sample test in Table 7 shows that $\mathrm{F}=2.812$, and the two-tailed test is significant $(\mathrm{P}=0<.01)$, which demonstrates that there are significant differences between scores of the contrastive class and the teaching experiment class after the teaching experiment was conducted.

Table 7. Independent Samples Test

\begin{tabular}{|l|c|c|c|c|c|}
\hline \multirow{2}{*}{} & \multicolumn{2}{|c|}{$\begin{array}{c}\text { Levene's Test for Equality } \\
\text { of Variances }\end{array}$} & & & \\
\cline { 2 - 6 } & $\boldsymbol{F}$ & $\boldsymbol{S i g .}$ & $\boldsymbol{t}$ & $\boldsymbol{d f}$ & Sig.(2-tailed) \\
\hline Equal variances assumed & 2.812 & .097 & -12.622 & 84 & .000 \\
\hline Equal variances not assumed & & & -12.622 & 80.227 & .000 \\
\hline
\end{tabular}

In conclusion, after the teaching experiment, the class which received the teaching experiment has improve much in the achievements of English idioms acquisition more than the contrastive class which received no experiment. Therefore, the S-S-P-C model of English idioms acquisition is proved to be efficient and be suitable for Chinese college students. 


\section{Conclusion}

To sum up, the general aim of the present study is to construct a model of English idioms acquisition suitable for Chinese college students, and the present study have solved the questions put forward in the introduction of the present thesis. The following conclusions can be drawn.

1. English idioms acquisition is not haphazard, instead, there is a pattern to follow.

Chinese college students need to acquire idioms by following a scientific acquisition modelinstead of only by rote learning.

2. English idioms acquisition needs to be dealt with from the four perspectives: syntactic, semantic, pragmatic, and cultural, which can be called S-S-P-C model. Syntactic analysis is conducive to students' memorizing idioms' forms and grasp idioms' grammar usages. Semantic analysis helps students acquire figurative meanings of idioms from literal meanings of constituents. Pragmatic perspective makes students develop a pragmatic competence and use idioms appropriately in specified context. Cultural perspective is favorable for students' understanding English idioms in a penetrating way. For comprehending and acquiring idioms comprehensively, students need to integrate the four approaches.

3. The S-S-P-C model is proved to be feasible and efficient. After the model was appliedin the teaching experiment, the idiom exams result and the interview with some students show that they improved English idioms acquisition and became interested in English learning.

The present study constructed the S-S-P-C model of English idioms acquisition and applied it in the teaching experiment, which provides insights into idioms acquisition' efficient method different from traditional method characterized with rote learning. Both Chinese college students and their English teachers will be expected to get hints from it. Nevertheless, the present study has still some limitations. For practical reasons, only 40 Chinese college students participated in the teaching experiment for one semester. A larger sample of participants and a longer duration of the teaching experiment would make the S-S-P-C model more valid and reliable.

\section{Acknowledgement}

The study is supported by Guangxi Normal University for Nationalities in China: The study of English idioms' characteristics and English idioms comprehension (The number: 2016YB020) and 2014-2018 Youth fund program of foreign languages teaching research in the stage of China's elementary education (The number: JJWYQN2015096)

\section{$6 \quad$ References}

[1] Gibbs,R.W.,Jr.(1991). Semantic analyzability in children's understanding of idioms. Journal of Speech and Hearing Research, 34: 613 - 620. https://doi.org/10.1044/jshr.3403.613 
[2] Zhang hui, Yiming Yang and Jiexin Gu, Feng Ji. (2013)."ERP correlates of compositionality in Chinese idiom comprehension". Journal of Neurolinguistics 26: 89-112.

[3] Titone, D. A., \& Connine, C. M. (1994). Comprehension of idiomatic expressions: Effects of predictability and literality. Journal ofExperimental Psychology: Learning, Memory, and Cognition, 20: 1126 - 1138. https://doi.org/10.1037/0278-7393.20.5.1126

[4] Fernando, C. (2000). Idioms and idiomaticity. Shanghai: Shanghai Foreign Language Teaching Publishing House.

[5] Sandrine Le Sourn-Bissaoui, Stéphanie Caillies, Stéphane Bernard, Michel Deleau, \&Lauriane Brulé. (2012). Children's understanding of ambiguous idiomsand conversational perspective-taking. Journal of Experimental Child Psychology 112: 437 - 451. https://doi.org/10.1016/j.jecp.2012.02.003

\section{$7 \quad$ Authors}

Hui Chen is a lecturer at School of Foreign Studies, Guangxi Normal University for Nationalities, Chongzuo, China.

*Xianze Wu, corresponding author, is an associate professor at School of Foreign Studies, Guilin University of Technology, Guilin, China.

Article submitted 01 May 2017. Published as resubmitted by the authors 07 June 2017. 